\title{
Correction to: TCONS_00230836 silencing restores stearic acid-induced $\beta$ cell dysfunction through alleviating endoplasmic reticulum stress rather than apoptosis
}

Rui Guo ${ }^{1}$, Yunjin Zhang ${ }^{1}$, Yue Yu ${ }^{1}$, Shenghan Su${ }^{1+}$, Qingrui Zhao ${ }^{1+}$, Xia $\mathrm{Chu}^{1}$, Shenglong $\mathrm{Li}^{2^{*}}$, Huimin $\mathrm{Lu}^{1 *}$ and Changhao Sun ${ }^{1 *}$

Correction to: Genes Nutr 16, 8 (2021)

https://doi.org/10.1186/s12263-021-00685-5

Following publication of the original article [1], the authors flagged that an earlier version of the chr $7 \mathrm{had}$ been mistakenly written as chr 10 in Fig. $1 \mathrm{~A}$ and in the "Upregulation of lncRNA TCONS_00230836 expression in stearic acid-treated $\beta$-TC6 cells and islets of mice fed a high-stearic-acid diet" section of the Results.

The original article has been updated and the corrected version of Fig. 1 is provided in this correction.

The authors apologize for any inconvenience caused.

The original article can be found online at https://doi.org/10.1186/s12263021-00685-5

* Correspondence: Lishenglong_1982@163.com; Ihm_519@sina.com; changhaosun2002@163.com

${ }^{+}$Shenghan Su and Qingrui Zhao contributed equally to this work.

${ }^{2}$ General Surgery Department, The Second Affiliated Hospital of Harbin Medical University, Harbin, China

'Department of Nutrition and Food Hygiene (National Key Discipline), Public

Health College, Harbin Medical University, Harbin, Hei Longjiang province

150081, People's Republic of China

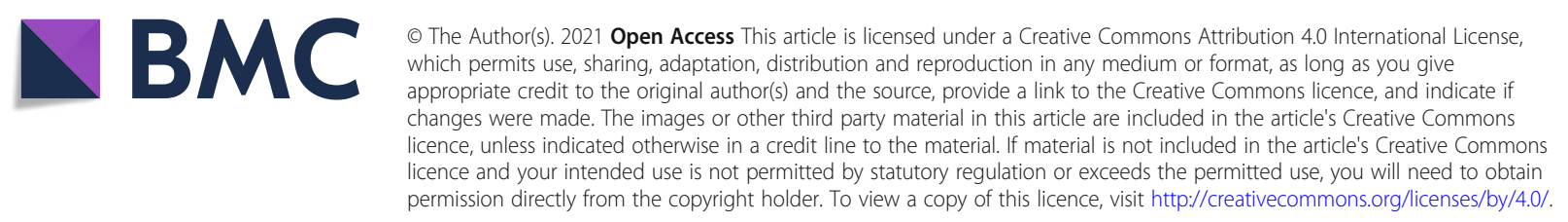




\begin{tabular}{|c|c|c|c|c|}
\hline IncRNA & & $\begin{array}{c}\log _{2} \text { Fold } \\
\text { change }\end{array}$ & $P$ value & Genomic location \\
\hline \multirow{2}{*}{$\begin{array}{c}\text { TCONS- } \\
00230836\end{array}$} & SA & 1.328 & $5.06 \mathrm{E}-07$ & \multirow{2}{*}{$\begin{array}{c}\text { chr7:65803111- } \\
65809116\end{array}$} \\
\hline & PA & 0.270 & 0.327 & \\
\hline
\end{tabular}

B

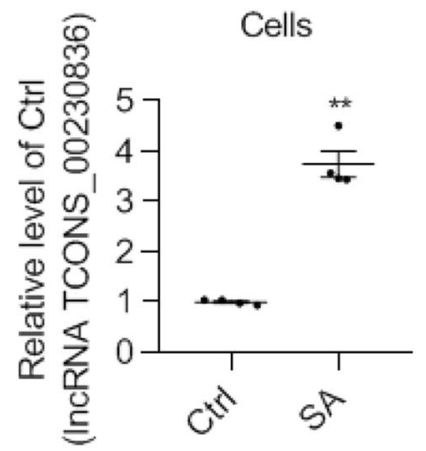

C

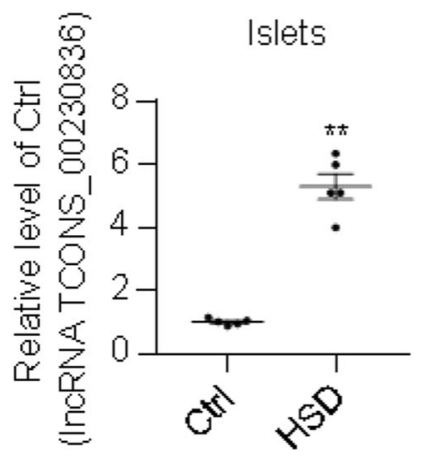

Fig. 1 LnCRNA TCONS_00230836 upregulation in stearic acid-treated $\beta$-TC6 cells and islets of mice fed a high-stearic-acid diet. a The studied IncRNA TCONS_00230836 with fold changes, $p$ values, and genomic locations in the presence of stearic acid and palmitic acid by RNA sequencing, respectively. ( $n=3$ per group) b qRT-PCR results verified that the level of the IncRNA TCONS_00230836 was elevated in stearic acidtreated $\beta$-TC6 cells. $(n=4)$ c The expression of the IncRNA TCONS_00230836 was also increased in the islets $(n=5)$ from mice fed a high-stearicacid diet, as revealed by qRT-PCR. Ctrl control group, SA stearic acid, PA palmitic acid, HSD high-stearic-acid diet. ${ }^{* *} p<0.01$, versus the Ctrl group

Published online: 12 July 2021

\section{Reference}

1. Guo R, Zhang Y, Yu Y, Su S, Zhao Q, Chu X, et al. TCONS_00230836

silencing restores stearic acid-induced $\beta$ cell dysfunction through alleviating endoplasmic reticulum stress rather than apoptosis. Genes Nutr. 2021;16:8 https://doi.org/10.1186/s12263-021-00685-5. 